\title{
Altered microsatellites in incomplete-type intestinal metaplasia adjacent to primary gastric cancers
}

\author{
T Hamamoto, H Yokozaki, S Semba, W Yasui, S Yunotani, K Miyazaki, E Tahara
}

\begin{abstract}
Aim-To investigate the presence of genetic instability in precancerous lesions of the stomach.

Methods-Fifteen cases of sporadic gastric cancers with a background of intestinal metaplasia were studied by microsatellite assay at nine loci. Altered metaplastic mucosa was microdissected, reconstructed topographically, and examined immunohistochemically with an anti-p53 antibody, comparing its positive area with foci of microsatellite instability in each individual.
\end{abstract}

Results-Alterations at one or more loci were observed in seven of 15 cancers (46.7\%) and four of 15 intestinal metaplasias $(26.7 \%)$. Two cases of replication error positive phenotype had no microsatellite alterations in their metaplastic mucosa. All the microsatellite alterations in the metaplastic mucosa were restricted to incomplete-type intestinal metaplasia around the respective cancers. Moreover, in one case, an identical pattern of microsatellite alteration was detected in the cancer tissue and in the adjacent metaplastic mucosa, suggesting the sequential development of gastric cancer from intestinal metaplasia. Frequent alteration was found at the locus D1S191 (1q), indicating that this locus might be altered early in the development of intestinal-type gastric cancer. No significant association between microsatellite instability and p53 immunoreactivity was observed in the cases examined.

Conclusion-These results indicate that microsatellite instability may be an early event in stomach carcinogenesis, especially in intestinal-type cancers.

(F Clin Pathol 1997;50:841-846)

Keywords: microsatellite instability; replication error; intestinal metaplasia; gastric cancer

Surgery, Saga Medical

School, Saga, Japan

T Hamamoto

$S$ Yunotan

K Miyazaki

Correspondence to:

Professor Tahara, First

Department of Pathology,

Hiroshima University School

of Medicine, 1-2-3 Kasumi,

Minami-ku, Hiroshima 734,

Japan.

Accepted for publication 28 July 1997

Gastric adenocarcinoma is classified histologically into two subtypes: well differentiated or intestinal-type, and poorly. differentiated or diffuse-type. ${ }^{12}$ Frequently, the former is accompanied by widespread intestinal metaplasia in the vicinity of the tumour, and is generally believed to arise via a multistage process, including chronic gastritis and intestinal metaplasia. ${ }^{3}$ These morphological changes from normal gastric epithelium may occur sequentially as a result of exogenous and endogenous factors that cause genetic alterations. Several molecular genetic studies have revealed that some well differentiated types of gastric cancer may develop by a cumulative series of gene changes similar to those that occur in colorectal cancer. ${ }^{4}$ In fact, in addition to cancer tissue, some gastric intestinal metaplasias show inactivation of the $\mathrm{p} 53^{5}$ and the APC genes, ${ }^{6}$ and reactivation of telomerase, indicating that metaplastic glands might be one of the precancerous lesions of the stomach. Moreover, we have detected microsatellite instability in one in three intestinal metaplasias of the stomach. ${ }^{8}$

Mutations in mismatch repair genes, such as hMSH2, hMLH1, hPMS1, hPMS2, and GTBP, responsible for maintaining the fidelity of DNA replication increase spontaneous mutation rates greatly. ${ }^{9-12}$ Microsatellites are simple oligonucleotide repeat units, distributed randomly and widely throughout the genome. The appearances of additions or deletions within the microsatellites are known as replication errors or microsatellite instability, and are believed to reflect derangement of the mismatch repair system. ${ }^{13}{ }^{14}$ Such genomic instability at microsatellite loci has been observed not only in hereditary non-polyposis colorectal cancer (HNPCC) associated tumours but also in certain sporadic cancers. ${ }^{15-17}$ As for gastric cancer, microsatellite instability has been reported with frequencies ranging from $18 \%$ to $38 \% .16$ 18-21

However, little is known about genomic instability in precancerous lesions of the stomach. To elucidate the role of genetic instability in the development of intestinal-type gastric cancer, we conducted a microsatellite assay on both resected intestinal-type sporadic gastric cancer tissues and the surrounding intestinal metaplastic mucosa. In addition, as microsatellite markers are useful as clonal markers, clonality of the somatic mutation within individual metaplastic mucosas and cancer tissues was also analysed by microdissection and topographical mapping.

\section{Methods}

PATIENTS AND TISSUE SAMPLES

Fifteen gastric cancers and corresponding samples of intestinal metaplasia were studied. All samples were obtained from surgery at Hiroshima University Hospital and Hiroshima Memorial Hospital. None of the patients met the Amsterdam criteria for HNPCC ${ }^{22}$ according to their family history collected from a review of medical records. Either non- 
Table 1 Results of microsatellite assay in gastric cancers and intestinal metaplasia

\begin{tabular}{|c|c|c|c|c|c|c|c|c|c|c|}
\hline \multirow[b]{2}{*}{ Case } & \multirow{2}{*}{$\begin{array}{l}\text { Intestinal } \\
\text { metaplasia }\end{array}$} & \multicolumn{9}{|c|}{ Microsatellite loci } \\
\hline & & $D 1 S 191$ & $D 7 S 486$ & $D 11 S 29$ & TP53 & $D 17 S 855$ & $B A T-R I I$ & $B A T-25$ & $B A T-26$ & $B A T-40$ \\
\hline 538 & Complete & $t^{\mathrm{T}}$ & $t^{\mathrm{T}}$ & $t^{T}$ & - & - & $t^{T}$ & $t^{T}$ & - & $t^{\mathrm{T}}$ \\
\hline 805 & Complete & $t^{\mathrm{T}}$ & NI & - & NI & ND & - & $t^{\mathrm{T}}$ & $t^{\mathrm{T}}$ & - \\
\hline 804 & Complete & $t^{\mathrm{T}}$ & - & - & ND & - & - & - & - & - \\
\hline 662 & Complete & ND & - & - & ND & ND & - & - & - & - \\
\hline 753 & Complete & - & - & - & NI & - & - & - & - & - \\
\hline 336 & Complete & ND & $\mathrm{LOH}^{\mathrm{M}}$ & ND & - & NI & - & - & - & - \\
\hline 834 & Incomplete & $t^{\mathrm{TM}}$ & ND & - & $\mathrm{LOH}^{\mathrm{TM}}$ & - & - & - & - & - \\
\hline 545 & Incomplete & $++^{\mathrm{TM}}$ & - & - & $\mathrm{LOH}^{\mathrm{T}}$ & - & - & - & - & - \\
\hline 742 & Incomplete & $+^{\mathrm{TM}}$ & - & - & $\mathrm{LOH}^{\mathrm{T}}$ & - & - & - & - & - \\
\hline 969 & Incomplete & - & - & - & $t^{\mathrm{TM}}$ & ND & - & - & - & - \\
\hline 784 & Incomplete & - & ND & - & ND & - & - & - & - & - \\
\hline 337 & Incomplete & - & ND & - & NI & - & - & - & - & - \\
\hline 368 & Incomplete & 一 & ND & - & - & - & - & - & - & - \\
\hline 665 & Incomplete & - & - & - & - & - & - & - & - & - \\
\hline 312 & Incomplete & - & NI & - & - & - & - & - & - & - \\
\hline
\end{tabular}

+ , microsatellite altered; - , microsatellite not altered; LOH, loss of heterozygosity; NI, not informative; ND, not determined; T, detected in tumour; $M$, detected in intestinal metaplasia; TM, detected in both tumour and intestinal metaplasia.

metaplastic normal mucosa or non-metastatic regional lymph node of the stomach was taken as a source of constitutive normal DNA. Tissues were fixed in $10 \%$ buffered formalin and embedded in paraffin. All tumours were intestinal-type gastric cancers comprising eight well differentiated and seven moderately differentiated tubular adenocarcinomas. Among these 15 subjects, 13 had single early cancers, one had single advanced cancer (extending into the muscularis propria), and one had double early cancers. Of the nonneoplastic mucosa, six revealed complete-type intestinal metaplasia and nine had incompletetype intestinal metaplasia. The definitions of histological classification, stage grouping, and depth of tumour invasion were according to those of the Japanese Research Society for Gastric Cancer. ${ }^{23}$ Intestinal metaplasia was classified by the morphological definition of Ming. ${ }^{24}$ Complete-type intestinal metaplasia is characterised by the presence of goblet cells, absorptive-type enterocytes, and Paneth cells, and incomplete-type intestinal metaplasia is characterised by the loss of Paneth cells, with mucous columnar cells in place of enterocytes.

DNA EXTRACTION

Haematoxylin and eosin stained serial $10 \mu \mathrm{m}$ sections of cancer tissues and non-neoplastic mucosa were dissected finely under the microscope. After deparaffinisation, DNA was extracted as described previously. ${ }^{8}$

\section{MICROSATELLITE ANALYSIS}

Nine microsatellite loci containing $(\mathrm{CA})_{\mathrm{n}}$ dinucleotide or poly $(A)_{n}$ repeat sequences were analysed in this study. Markers for (CA) repeat were D1S191, D7S486, D11S29, TP53 and D17S855 (Research Genetics, Huntsville,

Table 2 Frequency of microsatellite instability in gastric cancer and intestinal metaplasia

\begin{tabular}{lllll}
\hline & Cases $(n)$ & MI at single locus & MI at multiple loci & MI at least one locus \\
\hline Cancer & 15 & $5(33.3 \%)$ & $2(13.3 \%)$ & $7(46.7 \%)$ \\
Intestinal & & $4(26.7 \%)$ & 0 & $4(26.7 \%)$ \\
$\quad$ metaplasia & 15 & 0 & 0 & 0 \\
Complete & 9 & 4 & 0 & 4 \\
\hline Incomplete & 6 & & & \\
\hline
\end{tabular}

Alabama, USA) on chromosomes $1,7,11$, and 17; markers for poly $(A)_{n}$ tract were BAT-RII, BAT-25, BAT-26, and BAT- $40^{25}$ on chromosomes 1,2 , and 4 . The extracted DNA was amplified by polymerase chain reaction (PCR) using the same conditions as described previously. ${ }^{26}$ After $35-40$ cycles of PCR with $\left[\mathrm{r}^{32} \mathrm{P}\right]$ ATP labelled primer, the aliquots were fractionated on $6 \%$ polyacrylamide/ $8 \mathrm{M}$ urea/ $32 \%$ formamide gels. Following electrophoresis, the gels were fixed briefly in $10 \%$ methanol $/ 10 \%$ acetic acid, dried, and exposed at $-80^{\circ} \mathrm{C}$ to $x$ ray film. Tumours and metaplasias were judged as microsatellite instability positive if they demonstrated alterations in the size of the microsatellite sequences, compared with the product from the matched normal tissue. All markers for unstable cases were repeated for PCR and gel electrophoresis to confirm the results.

\section{IMMUNOHISTOCHEMISTRY}

A monoclonal antibody to p53 (DO7) was purchased from Novocastra (Newcastle upon Tyne, UK). A modification of the immunoglobulin enzyme bridge technique was used, as described previously. ${ }^{27}$ Deparaffinised and rehydrated sections were heated by microwave oven for 10 minutes in citrate buffer to retrieve antigen and were treated with anti-p53 antibody (diluted $1 / 1000$ ) at $4^{\circ} \mathrm{C}$ for eight hours. The immunoreactivity in the tissues was graded from - to +++ , according to the number of cells stained and the intensity of the reaction in individual cells. Grades were defined as follows: -, almost no positive cells; ,$+ 10-30 \%$ of tumour/metaplastic cells showing weak to moderate immunoreactivity; ++ , $30-60 \%$ of tumour/metaplastic cells showing moderate immunoreactivity and/or $10-30 \%$ of tumour/metaplastic cells showing intense immunoreactivity;,$+++>60 \%$ of tumour/ metaplastic cells showing intense immunoreactivity.

\section{Results}

MICROSATELLITE ALTERATIONS IN INTESTINAL-TYPE GASTRIC CANCERS

The results of the microsatellite assay in gastric cancers and intestinal metaplasia are 


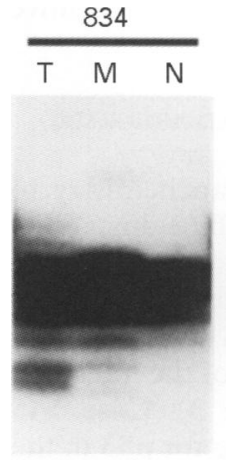

D1S191

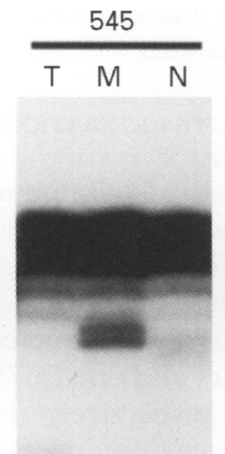

D1S191

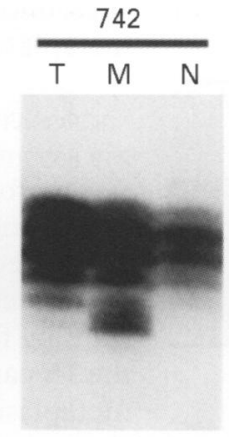

D1S191

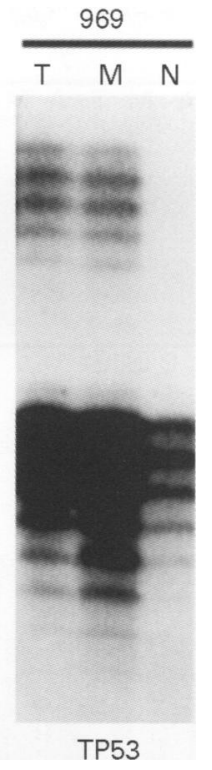

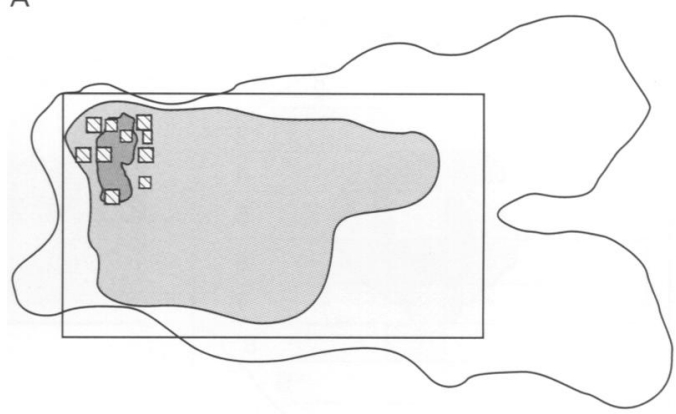

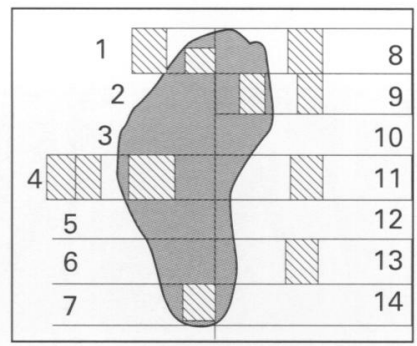

B

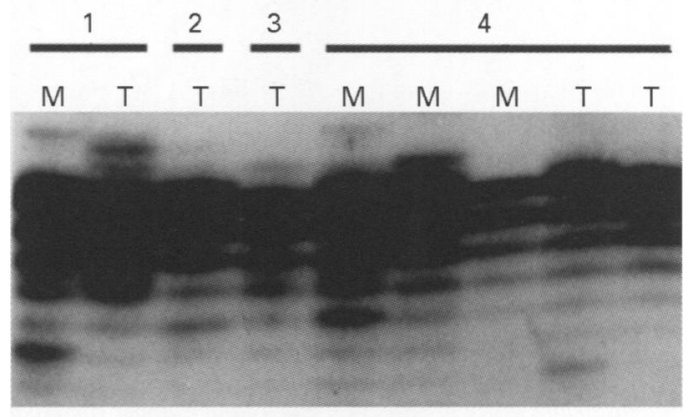

D1S191 obtained from non-HNPCC individuals. Their samples were microdissected and reexamined by microsatellite assay at altered loci. All the altered alleles in cancer tissue demonstrated the same pattern of alteration in each individual (data not shown). No significant difference in the incidence of microsatellite instability was found between (CA) repeat markers and poly $(A)_{n}$ tract markers. Interestingly, frequent alteration (six of 15) was detected at the locus D1S191 on the long arm of chromosome 1. Loss of heterozygosity was observed infrequently at several loci, but was not regarded as microsatellite instability.

MICROSATELLITE ALTERATIONS IN INTESTINAL METAPLASIA OF THE STOMACH

Four of 15 intestinal metaplasias (26.7\%) revealed microsatellite instability at a single locus, as well as in corresponding cancer tissue (fig 1). All four were incomplete-type intestinal metaplasia lacking Paneth cells (table 2). On the other hand, intestinal metaplasias of two cases with sporadic replication error positive phenotypes in the cancer tissues did not harbour alteration at any microsatellite loci, which was confirmed using microdissecting samples of case 538 (data not shown).

Figure 2 (A) Topographical distribution of a microsatellite instability positive lesions in case 834 . The top panel is an illustration of a resected stomach and the bottom panel is a magnification of the lesions around the tumour. The square frame in the top panel indicates the area examined by the microsatellite assay. A total of 80 samples was analysed. Specimen numbers are indicated. Light grey, intestinal metaplasia; dark grey, tumour; cross-hatch, microsatellite instability altered lesion. (B) $A$ representative autoradiograph of a microsatellite assay of case 834. Each lane number corresponds to the specimen number. T, tumour; $M$, intestinal metaplasia. $A$ different pattern of microsatellite alteration is seen in the field of cancer (1T and 4T) compared with that seen in the adjacent metaplastic mucosa (1M and $4 M$ ) at the locus D1S191.

TOPOGRAPHICAL DISTRIBUTION OF MICROSATELLITE ALTERATIONS IN INTESTINAL METAPLASIA OF THE STOMACH

The topographical distributions of microsatellite alteration in microsatellite instability positive metaplasia was investigated. Distributions of microsatellite instability were determined using microdissected samples. Representative cases of microsatellite instability positive metaplasia are shown in figs 2 and 3. A mapping study demonstrated that all the microsatellite alterations in metaplastic mucosa were restricted to small areas, all of which were adjacent to respective cancers (fig $2 \mathrm{~A}$ ). Analysing the pattern of altered alleles, three cases had different alleles with altered microsatellites 


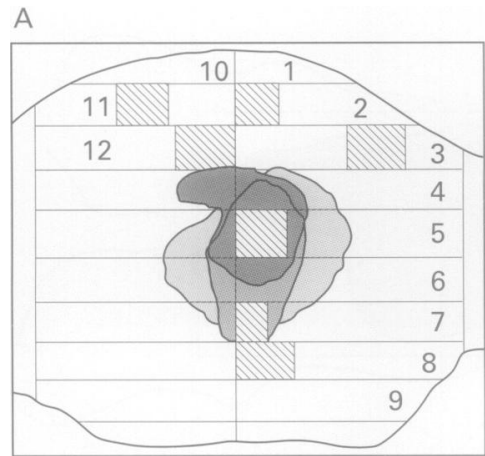

B
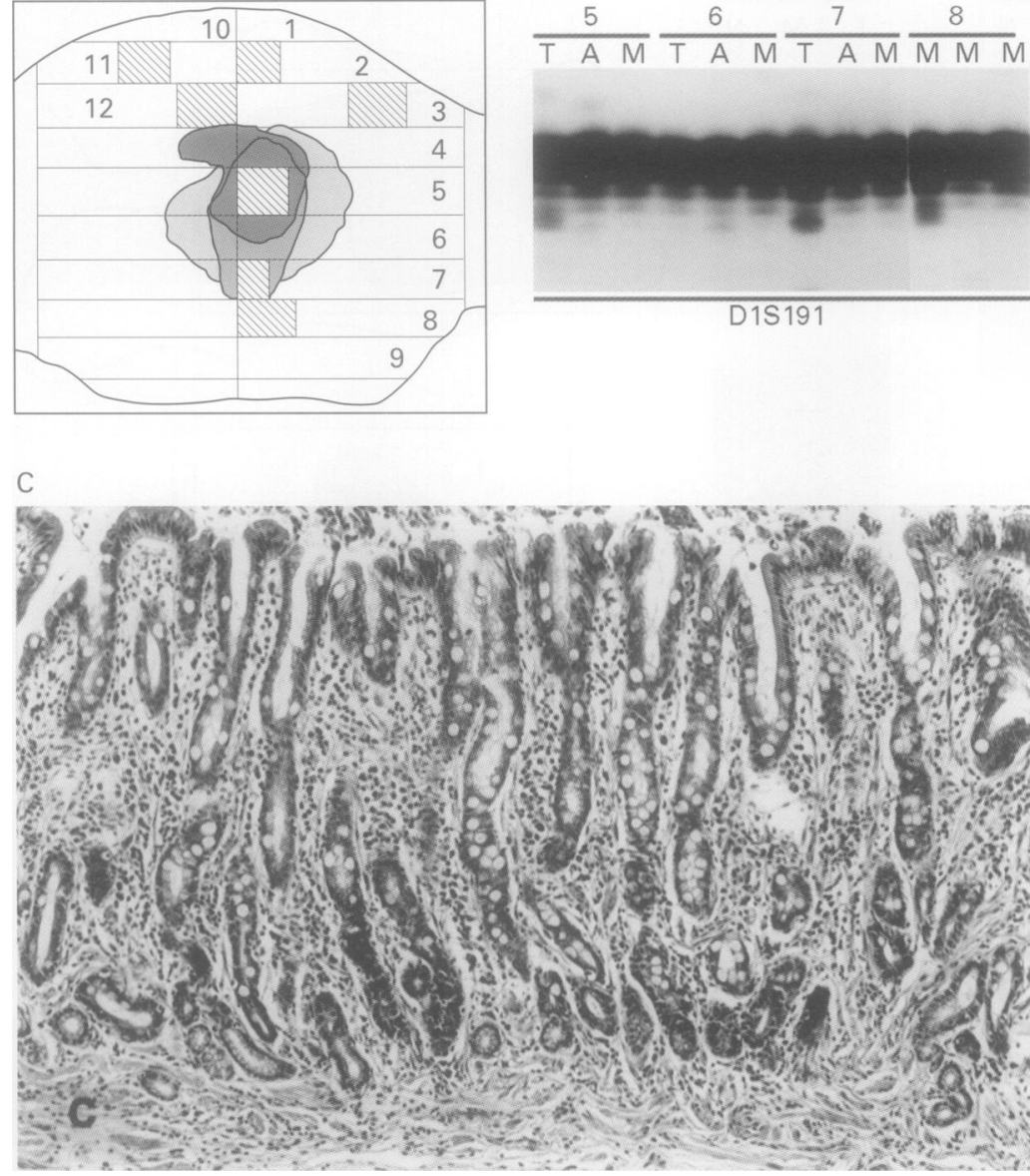

Figure 3 (A) Topographical distribution of microsatellite instability and $p 53$ positive lesions in case 545. A total of 47 samples was analysed. Specimen numbers are indicated. Medium grey, tumour; light grey, tubular adenoma; cross-hatch, microsatellite instability altered lesion; dark grey, 553 positive lesion. (B) $A$ representative autoradiograph of a microsatellite assay of case 545. Each lane number corresponds to the specimen number. $T$, tumour; $A$, tubular adenoma; $M$, intestinal metaplasia. Identical and sequential microsatellite alteration is found in the tumour (7T) and adjacent intestinal metaplasia (8M) at the locus D1S191. (C) Microphotograph of microsatellite instability positive metaplasia, specimen 8 from case 545 .

Table 3 Microsatellite instability and p53 status on the cases of gastric cancers with intestinal metaplasia

\begin{tabular}{|c|c|c|c|c|}
\hline \multirow[b]{2}{*}{ Case } & \multicolumn{2}{|c|}{ Microsatellite instability } & \multicolumn{2}{|c|}{ p53 immunoreactivity } \\
\hline & Tumour & Intestinal metaplasia & Tumour & Intestinal metaplasia \\
\hline 538 & + & - & + & - \\
\hline 805 & + & - & - & - \\
\hline 804 & + & - & ++ & - \\
\hline 662 & - & - & - & - \\
\hline 763 & - & - & - & - \\
\hline 336 & - & - & - & - \\
\hline 834 & + & + & - & - \\
\hline 545 & + & + & ++ & + \\
\hline 742 & + & + & +++ & - \\
\hline 969 & + & + & - & - \\
\hline 784 & - & - & - & - \\
\hline 337 & - & - & ++ & - \\
\hline 368 & - & - & - & - \\
\hline 665 & - & - & ++ & - \\
\hline 312 & - & - & - & - \\
\hline
\end{tabular}

in the field of cancer tissue and adjacent metaplastic mucosa (fig 2B). Interestingly, in case 545 , identical and sequential microsatellite alteration was observed in both the cancer tissue and adjacent intestinal metaplasia at the locus D1S191 (figs 3A and B). Histologically, most of the altered epithelium demonstrated intestinal metaplasia with chronic inflammation and mild atypia compared with the surrounding microsatellite instability negative metaplastic glands (fig 3C).

MICROSATELLITE ALTERATIONS AND ABNORMAL P53 EXPRESSION

We performed p53 immunohistochemistry to determine whether microsatellite instability correlated with p53 immunoreactivity in gastric intestinal metaplasia. Positive nuclear staining for p53 was detected in six $(40.0 \%)$ of the 15 cancers and one $(6.7 \%)$ of the intestinal metaplasias, respectively (table 3). Case 545 showed positive immunostaining for $\mathrm{p} 53$ in the lower half of the incomplete-type metaplastic glands as well as in the cancer cells. Because the p53 positive area did not coincide with that of the microsatellite alterations (fig $3 \mathrm{~A}$ ), there seemed to be no significant association between microsatellite instability and abnormal accumulation of p53 protein in intestinal metaplasia of the stomach.

\section{Discussion}

In this series of intestinal-type gastric cancers, we found microsatellite instability in seven of 15 cancers $(46.7 \%)$ in at least one locus after examining nine loci; this frequency is slightly higher than that reported previously. ${ }^{821}$ Two cases with microsatellite instability at more than three loci were regarded as replication error positive cancers because widespread microsatellite instability was comparable to the typical microsatellite instability described in HNPCC associated tumours and represented defects in the mismatch repair system. ${ }^{28}$ In addition, one of them had an alteration of 10 base pair poly (A) tract of the transforming growth factor $\beta$ type II receptor, which is a critical target of inactivation in mismatch repair deficient tumours. ${ }^{25} 29$

The main purpose of the present study was to clarify the existence of microsatellite instability in intestinal metaplasia, which is implicated in stomach carcinogenesis. We detected microsatellite alterations in four of 15 foci of metaplasia $(26.7 \%)$ at a single locus, indicating that irreversible genetic changes exist in metaplastic glands of the stomach.

In addition, we investigated microsatellite instability in intestinal metaplasia of the stomach by analysing its topographical distribution and allelic pattern. First, microsatellite instability positive metaplasias were separated into small foci, but all of them were restricted to adjacent areas of the respective cancers. Also, the majority of altered alleles exhibited heterogeneous patterns, suggesting that they might not have a common clonal origin. Interestingly, in case 545, an identical and sequential alteration pattern was observed in the cancer tissue as well as in the adjacent metaplastic mucosa, indicating single clonal origin and sequential tumour development from intestinal metaplasia. From the histological point of view, microsatellite instability positive metaplasias of four cases were incomplete-type with regenerative atypia and chronic inflammation.

Our observations suggest that microsatellite instability may occur multiclonally within certain fields of the gastric epithelium showing 
incomplete-type intestinal metaplasia, and some of the gastric cancers may develop from intestinal metaplasia. Therefore, microsatellite instability may represent an early genetic alteration in the development of intestinal-type gastric cancer. Moreover, p53 mutations have been detected in incomplete-type intestinal metaplasia. ${ }^{30}$ Taken together, incomplete-type metaplastic glands of the stomach can be viewed as genetically unstable.

What is more interesting is the altered number of microsatellite loci in intestinal metaplasia. All microsatellite instabilities in intestinal metaplasia were detected at a single locus. On the other hand, we could not detect microsatellite instability in intestinal metaplasia surrounding two replication error positive phenotype gastric cancers. Gleeson et al described two types of genomic instability; widespread microsatellite instability and low level microsatellite instability, based on the mutated number of microsatellite markers tested and such low level instability may reflect the inherent instability at microsatellite markers. ${ }^{28}$ Microsatellite instability in intestinal metaplasias may reflect the inherent instability at each microsatellite locus. Seruca et al found that most replication error positive gastric cancers displayed abundant $\mathrm{T}$ lymphocyte infiltration. ${ }^{31}$ Gastric epithelium with continuous inflammation might have been exposed to a variety of carcinogens that could facilitate increased mutagenesis, leading to the low level microsatellite instability. In the present study, frequent instability in both intestinal-type cancer and intestinal metaplasia of the stomach was observed at D1S191 on chromosome 1q. It is likely that this locus is a specific fragile site that may be linked with stomach carcinogenesis.

However, it is still unclear whether microsatellite instability plays a pivotal role in stomach carcinogenesis, because most microsatellite instability occurs in non-coding DNA, that is, within introns or intergenic regions of the genome. On the other hand, alterations in the p53 gene are observed in over $60 \%$ of gastric cancer cases, regardless of histological type. Moreover, they take place even in the mucosal cancers and in intestinal metaplasia. ${ }^{32} 33$ Among 15 intestinal metaplasias of the stomach, we observed positive nuclear staining for p53 in only one case (case 545), which revealed microsatellite instability at different metaplastic mucosa. However, it was difficult to distinguish morphologically between microsatellite instability positive metaplastic glands and p53 positive metaplastic glands. Therefore, there seems to be no apparent association between microsatellite instability and p53 alteration.

In conclusion, our results demonstrate that microsatellite instability occurs frequently in the incomplete type of intestinal metaplasia, a condition that can be viewed as a precancerous lesion of the stomach. Furthermore, it is suggested that microsatellite alterations could be useful as a biomarker for the clinical evaluation of the malignant potential of gastric non-neoplastic mucosa.
This work was supported in part by a Grant-in-Aid for Cancer Research from the Ministry of Health and Welfare for the Comprehensive 10-Year Strategy for Cancer Control and from the Ministry of Education, Science, Culture and Sports, Japan.

1 Lauren $P$. The two histological main types of gastric carcinoma: diffuse and so-called intestinal-type carcinoma. Acta Pathol Microbiol Scand 1965;64:31-9.

2 Nakamura $K$, Sugano $H$, Takagi $K$, Kumakura $K$. Histogenesis of carcinoma of the stomach with special reference to 50 primary microcarcinomas. Light-and electron-microscopic, and statistical studies. $\mathscr{f p n} \mathcal{f} \mathrm{Cancer}$ Clin 1967;15:627-47.

3 Correa P. The new era of cancer epidemiology. Cancer Epidemiol Biomarkers Prev 1991;1:5-11.

4 Fearon ER, Vogelstein B. A genetic model for colorectal tumorigenesis. Cell 1990;61:759-67.

5 Tahara E, Kuniyasu H, Yasui W, Yokozaki H. Gene alterations in intestinal metaplasia and gastric cancer. Eur $\mathcal{f}$ Gastroenterol Hepatol 1994;6:97-102.

6 Nishimura K, Yokozaki H, Haruma K, Kajiyama G, Tahara E. Alterations of the APC gene in carcinoma cell lines and precancerous lesions of the stomach. Int $\mathcal{F}$ Oncol 1995;77: 587-92.

7 Tahara H, Kuniyasu H, Yokozaki H, Yasui W, Shay JW, Ide $\mathrm{T}$, et al. Telomerase activity in preneoplastic and neoplastic gastric and colorectal lesions. Clin Cancer Res 1995;1:124551 .

8 Semba S, Yokozaki H, Yamamoto S, Yasui W, Tahara E. Microsatellite instability in precancerous lesions and adenocarcinomas of the stomach. Cancer Suppl 1996;77: 1620-7.

9 Fishel R, Lescoe MK, Rao MRS, Copeland NG, Jenkins NA, Garber J, et al. The human mutator gene homolog $\mathrm{MSH} 2$ and its association with hereditary nonpolyposis colon cancer. Cell 1993;75:1027-38.

10 Bronner CE, Baker SM, Morrison PT, Warren G, Smith LG, Lescoe MK, et al. Mutation in the DNA mismatch repair gene homologue hMLH1 is associated with hereditary non-polyposis colon cancer. Nature 1994;368: 258-61.

11 Nicholaides NC, Papadopoulos N, Liu B, Wei YF, Carter KC, Ruben SM, et al. Mutations of two PMS homologues in hereditary nonpolyposis colon cancer. Nature 1994;371: 75-80.

12 Papadopoulos N, Nicolaides NC, Liu B, Parsons R, Lengauer C, Palombo F, et al. Mutations of GTBP in genetically unstable cells. Science 1995;268:1915-7.

13 Aaltonen LA, Peltomäki P, Leach FS, Sistonen P, Pylkkänen $\mathrm{L}$, Mecklin JP, et al. Clues to the pathogenesis of familial colorectal cancer. Science 1993;260:812-16.

14 Wu C, Akiyama Y, Imai K, Miyake S, Nagasaki $H$, Oto $M$, et al. DNA alterations in cells from hereditary non-polyposis colorectal cancer patients. Oncogene 1994;9:991-4.

15 Thibodeau SN, Bren G, Schaid D. Microsatellite instability in cancer of the proximal colon. Science 1993;260:816-19.

16 Peltomäki P, Lothe RA, Aaltonen LA, Pylkkänen L, Nyström-Lahti M, Seruca R, et al. Microsatellite instability is associated with tumors that characterize the hereditary non-polyposis colorectal carcinoma syndrome. Cancer Res 1993;53:5853-5.

17 Burks RT, Kessis TD, Cho KR, Hedrick L. Microsatellite instability in endometrial carcinoma. Oncogene 1994;9: 1163-6.

18 Han H-J, Yanagisawa A, Kato Y, Park J-G, Nakamura Y. Genetic instability in pancreatic cancer and poorly differentiated types of gastric cancer. Cancer Res 1993;53: differentiate

19 Strickler JG, Zheng J, Shu Q, Burgart LJ, Alberts SR, shibata D. p53 mutations and microsatellite instability in sporadic gastric

20 Rhyu M-G, Park W-S, Meltzer SJ. Microsatellite instability occurs frequently in human gastric carcinoma. Oncogene 1994;9:29-32.

21 Chung Y-J, Song J-M, Lee J-Y, Jung Y-T, Seo E-J, Choi S-W, et al. Microsatellite instability-associated mutations associate preferentially with the intestinal type of primary gastric carcinomas in a high-risk population. Cancer Res 1996;56:
4662-5.

22 Vasen HFA, Mecklin J-P, Khan PM, Khan HT. The international collaborative group on hereditory nonpolyposis colorectal cancer. Dis Colon Rect 1991;34:424-5.

23 Japanese Research Society for Gastric Cancer. Fapanese classification of gastric carcinoma. 1st English edn. Tokyo: Kanehara, 1995.

24 Ming SC, Goldman H, Frieman DG. Intestinal metaplasia and histogenesis of carcinoma in human stomach. Light and electron microscopic study. Cancer 1967;20: 1418-29.

25 Parsons R, Myeroff LL, Liu B, Willson JKV, Markowitz SD, Kinzler KW, et al. Microsatellite instability and mutations of the transforming growth factor $\beta$ type II receptor gene in colorectal cancer. Cancer Res 1995;55:5548-50.

26 Horii A, Han H-J, Shimada M, Yanagisawa A, Kato Y, Ohta H. Frequent replication errors at microsatellite loci in tumors of patients with multiple primary cancers. Cancer tumors of patients with
Res $1994 ; 54: 3373-5$.

27 Yasui W, Ji Z-Q, Kuniyasu H, Tahara E. Expression of transforming growth factor alpha in human tissues: immunohistochemical study and Northern blot analysis. Virchows Arch A Pathol Anat Histopathol 1992;421:513-19. 
28 Gleeson CM, Sloan JM, McGuigan JA, Ritchie AJ, Weber JL, Russell SEH. Ubiquitous somatic alterations at microsatellite alleles occur infrequently in Barrett'sassociated esophageal adenocarcinoma. Cancer Res 1996;
56:259-63. 56:259-63.

Markowitz S, Wang J, Myeroff L, Parsons R, Sun L, Lutterbaugh J, et al. Inactivation of the type II TGF- $\beta$ receptor in colon cancer cells with microsatellite instability. Science 1995;268:1336-8.

30 Ochiai A, Yamauchi Y, Hirohashi S. p53 mutations in the non-neoplastic mucosa of the human stomach showing intestinal metaplasia. Int $\mathcal{f}$ Cancer 1996;69:28-33.
31 Seruca R, Santos NR, David L, Constancia M, Barroca H, Carneiro F, et al. Sporadic gastric carcinomas with microsCarneiro F, et al. Sporadic gastric carcinomas with microsatellite instability display a particul
profile. Int $\mathcal{F}$ Cancer 1995;64:32-6.

32 Yokozaki H, Kuniyasu H, Kitadai Y, Nishimura K, Todo H, Ayhan A, et al. p53 point mutations in primary human gastric carcinomas. 7 Cancer Res Clin Oncol 1992;119:6770.

33 Shiao YH, Rugge M, Correa P, Lehmann HP, Scheer WD. p53 alteration in gastric precancerous lesions. Am $\mathcal{F}$ Pathol 1994;144:511-17. 